\title{
Efeitos do enfoque patrimonial na dívida pública flutuante: um estudo de caso em uma fundação pública do norte do Brasil
}

\author{
Effects of asset approach on floating public debt: a case study in a public foundation in \\ northern Brazil
}

Efectos del enfoque patrimonial en la deuda pública flotante: un estudio de caso en una fundación pública del norte de Brasil

\section{Jonathan Alves Galdino}

Mestre em Contabilidade e Controladoria na Universidade Federal do Amazonas Especialista em Planejamento Governamental e Orçamento Público na Universidade do Estado do Amazonas

Contador no Departamento Financeiro da Universidade Federal do Amazonas

Endereço: Avenida General Rodrigo Octávio, nº 6200, Bairro Coroado I

CEP: 69077-000 - Manaus/AM - Brasil

E-mail: jonathangaldino@gmail.com

\section{Joel Brito Moura}

Especialista em Planejamento Governamental e Orçamento Público na Universidade do Estado do Amazonas

Assessor no Setor Fiscal da Secretaria de Estado da Fazenda do Amazonas

Endereço: Avenida André Araújo, $\mathrm{n}^{\circ}$ 150, Bairro Aleixo

CEP: 69060-000 - Manaus/AM - Brasil

E-mail: joel_brito@msn.com

\section{Edileuza Lobato da Cunha}

Mestre em Engenharia de Produção na Universidade Federal do Amazonas Professora do Programa de Pós-Graduação Lato Sensu em Planejamento Governamental e Orçamento Público da Universidade do Estado do Amazonas

Endereço: Rua 10 de Julho, ${ }^{\circ}$ 873, Bairro Centro

CEP: 69010-060 - Manaus/AM - Brasil

E-mail: edileuza@uninorte.com.br

Artigo recebido em 14/04/2014. Revisado por pares em 10/06/2014. Reformulado em 11/07/2014. Recomendado para publicação em 18/07/2014 por Sandra Rolim Ensslin (Editora Científica). Publicado em 28/08/2014. 


\title{
Resumo
}

Com a convergência da Contabilidade Pública às Normas Internacionais, espera-se uma melhor evidenciação do patrimônio público. Esse estudo objetiva investigar os efeitos da adoção do enfoque patrimonial sobre a Dívida Pública Flutuante a partir da realização de um estudo de caso em uma fundação estadual do Norte do Brasil e do emprego de análise de clusters. Verificou-se uma subavaliação de 51,56\% da Dívida Flutuante da entidade pública analisada. Concluiu-se, como efeitos da adoção do enfoque patrimonial na Dívida Flutuante das entidades públicas, uma melhoria na evidenciação qualitativa e quantitativa do Passivo.

Palavras-chave: Contabilidade pública. Dívida pública flutuante. Enfoque patrimonial.

\begin{abstract}
With the convergence of the Public Accounting to International Standards, it is expected a better disclosure of public property. This study aims to investigate the effects of the adoption of the asset approach on Floating Public Debt from conducting a case study in a state foundation in Northern Brazil and the use of clusters analysis. It has been observed an underestimation of $51.56 \%$ of the floating debt of the public entity analyzed. We conclude, as effects of the adoption of the asset approach in the Floating Debt of public entities, there is an improvement in the qualitative and quantitative disclosure of liabilities.
\end{abstract}

Key-words: Public accounting. Floating public debt. Asset approach.

\section{Resumen}

Con la convergencia de la Contabilidad Pública a las Normas Internacionales, se espera una mejor revelación del patrimonio público. Este estudio tiene como objetivo investigar los efectos de la adopción del enfoque patrimonial sobre la Deuda Pública Flotante a partir de la realización de un estudio de caso en una fundación estatal del Norte de Brasil y del empleo de análisis de clusters. Ha sido constatada una infravaloración de 51,56\% de la Deuda Flotante de la entidad pública analizada. Concluimos, como efectos de la adopción del enfoque patrimonial en la Deuda Flotante de las entidades públicas, una mejora en la revelación cualitativa y cuantitativa del Pasivo.

Palabras clave: Contabilidad pública. Deuda pública flotante. Enfoque patrimonial. 


\section{Introdução}

Desde 2011, há temor acerca de uma recessão econômica mundial em detrimento do que os analistas chamam de "segundo estágio" da crise financeira internacional, centrada nos países europeus, principalmente nos da Zona do Euro, iniciada em 2007, quando o sistema financeiro norte-americano entrou em colapso por causa do estouro da bolha de seu mercado imobiliário residencial, configurando-se na maior crise do sistema capitalista depois da Grande Depressão em 1929. Entre as causas da crise econômica europeia, está o crescimento da dívida pública associado a um fraco desempenho econômico dos países europeus em crise (BEM, 2013).

A dívida pública europeia, por sua vez, trouxe à tona percalços relacionados ao disclosure das receitas e das despesas dos entes públicos e tem provocado debates sobre transparência e accountability governamental pelos pesquisadores das Ciências Sociais Aplicadas (ANDRADE; CARVALHO, 2013). De acordo com os ensinamentos de Iudícibus (2010), disclosure está imbricado no objetivo da Contabilidade, pois trata da evidenciação de informações diferenciadas sobre o patrimônio das entidades para os diversos tipos de usuários da informação contábil.

Ball (2012) declara que, de um modo geral, os governos estão demonstrando muito mal sua posição e seu desempenho financeiro. Ocorre que alguns sistemas políticos, como as democracias representativas, exigem maior accountability e transparência governamental que sistemas políticos autoritários e totalitários. Em se tratando de democracias representativas, como é o caso dos países desenvolvidos e dos países em desenvolvimento, o governo é obrigado a ser mais sensível ao atendimento das demandas de informações que lhe são requeridas (CHAN, 2010).

Nesse sentido, a Contabilidade Patrimonial, baseada no regime contábil de competência, em países em desenvolvimento como o Brasil, tem papel fundamental na promoção da transparência e da accountability (CHAN, 2010). Coelho, Cruz e Platt Neto (2011) expressam que a Contabilidade é uma ciência que possibilita aos cidadãos o acesso a informações completas, confiáveis e oportunas acerca dos atos e fatos públicos advindos de decisões políticas que permeiam toda a vida social.

No Brasil, desde a sua origem, a Contabilidade Pública sempre esteve enfatizada no acompanhamento e no controle da execução orçamentária de receitas e despesas. Antes do processo de convergência às Normas Internacionais, a Contabilidade Pública era traduzida, predominantemente, como execução orçamentária. Conceição (2012) declara que essa vinculação da Contabilidade Pública a assuntos fundamentalmente orçamentários pode ser explicada pela ênfase dada, no passado, à legalidade dos normativos orçamentários e ao orçamento público, deixando a evidenciação do patrimônio público em segundo plano.

Com a convergência da Contabilidade Pública brasileira às Normas Internacionais e a consequente adoção do enfoque patrimonial no registro atos e fatos públicos, espera-se a desvinculação de assuntos estritamente orçamentários e o registro correto, completo, confiável e oportuno do patrimônio público (CONCEIÇÃ̃, 2012). A falta de informação completa, confiável e oportuna sobre obrigações financeiras de um governo enfraquece sua capacidade e seu incentivo de cumprimento de suas responsabilidades. Um governo que não é capaz de confrontar seus Ativos e Passivos financeiros, de modo completo, confiável e oportuno, pode ter sérios problemas de liquidez e solvência, os quais levariam a uma crise 
fiscal de grandes proporções (CHAN, 2010) como a que está sendo combatida, atualmente, na Zona do Euro.

Desse contexto, surge a seguinte questão de pesquisa: Quais os efeitos da adoção do enfoque patrimonial pela Contabilidade Aplicada ao Setor Público no endividamento público flutuante das entidades governamentais? Assim sendo, este estudo objetiva investigar os efeitos da adoção do enfoque patrimonial sobre a Dívida Pública Flutuante das entidades governamentais, com base na realização de um estudo de caso em uma fundação pública estadual da região Norte do Brasil e do emprego de análise de clusters, por meio de pesquisa exploratória, descritiva e documental, baseada em dados primários, com abordagem qualitativa e quantitativa.

A fragilidade da presente pesquisa reside no fato de que estudos de caso não costumam oferecer muitas bases para generalizações científicas e não possuem condução metodológica bem definida pela literatura como ocorre com as análises estatísticas (YIN, 2010). Todavia, os resultados alcançados e as contribuições esperadas com este estudo não são invalidados por essa fragilidade, haja vista suas conclusões poderem servir de parâmetro de comparação para pesquisas semelhantes aplicadas em outras entidades públicas. Além do mais, os critérios de análise de resultados adotados, neste estudo, são argumentos válidos, imparciais, replicáveis e sistemáticos.

\section{Referencial Teórico}

\subsection{Aspectos legais e teóricos acerca da Dívida Pública Flutuante}

Entende-se por Dívida Pública Flutuante a dívida contraída pelos entes da Federação por um curto e determinado período, geralmente, um exercício financeiro, na qualidade de administradores de recursos de terceiros confiados à sua guarda ou para atendimento momentâneo de necessidades de caixa (PIRES, 2007).

A Lei Federal n 4.320/1964, em seu art. 92, declara que a Dívida Pública Flutuante é composta por Restos a Pagar menos os serviços da dívida, por serviços da dívida, por depósitos e por débitos de tesouraria. Débitos de tesouraria são dívidas de natureza extraorçamentária efetuadas para atendimento de insuficiência de caixa do governo, oriundas de operações denominadas ARO (Antecipação de Receita Orçamentária), que são uma espécie de empréstimo a curto prazo. Serviços da dívida a pagar são as parcelas de amortização e juros da Dívida Pública Fundada ou Consolidada, vincendas até o final do exercício financeiro subsequente ao do fechamento do Balanço Patrimonial. Os depósitos são recursos de terceiros provenientes de cauções ou garantias contratuais ou das consignações decorrentes de folha de pagamento de salários ou de substituição tributária (JUND, 2008). Restos a Pagar são despesas orçamentárias realizadas, mas não pagas até o dia 31 de dezembro do exercício corrente, ficando para serem pagas no exercício subsequente, dividindo-se em processadas, quando a despesa passou pelo estágio de liquidação, e não processadas quando a despesas permaneceu apenas na fase do empenho e não houve liquidação (PIRES, 2007).

Em suma, a Dívida Flutuante, também denominada de Dívida Administrativa ou Não Consolidada, caracteriza-se por indicar débitos de curto prazo, cujos pagamentos independem de autorização legislativa por se tratarem de compromissos assumidos por prazo inferior a 12 
meses (KOHAMA, 2008). A Dívida Pública Flutuante, que integra o Passivo Financeiro das entidades governamentais (BEZERRA FILHO, 2008), é evidenciada no Balanço Patrimonial, nos termos do inciso I do parágrafo $3^{\circ}$ do art. 105 da Lei Federal $n^{\circ} 4.320 / 1964$, dispõe que o Balanço Patrimonial demonstrará, entre outros grupos de contas, o Passivo Financeiro e que este compreenderá as Dívidas Fundadas e outras, cujo pagamento independa de autorização orçamentária.

Ocorre que, com adoção do enfoque patrimonial e consequente regime de competência integral no registro e evidenciação do patrimônio público, decorrente do processo de convergência da Contabilidade Pública brasileira às Normas Internacionais, a Dívida Pública Flutuante, cujos fatos geradores já tenham ocorrido e foram reconhecidos, embora continue sendo evidenciada no Balanço Patrimonial, passa a configurar no grupo de contas do Passivo Circulante, outrora, Passivo Financeiro.

A NBC T 16.2 estrutura o patrimônio público, sob o enfoque contábil ou patrimonial, em três grupos: Ativos; Passivos e Patrimônio Líquido. A NBC T 16.2 também conceitua Passivo como "obrigações presentes da entidade, derivadas de eventos passados, cujos pagamentos se esperam que resultem para a entidade saídas de recursos capazes de gerar benefícios econômicos ou potencial de serviços". Em adição, declara que a segregação em "Circulante" e "Não Circulante" deve considerar os aspectos de conversibilidade e exigibilidade e que os Passivos devem ser classificados como Circulantes quando corresponderem a valores exigíveis até 12 meses da data das demonstrações contábeis; quando forem pagos durante o ciclo operacional normal da entidade e/ou quando forem mantidos essencialmente para fins de negociação.

Segundo Slomski (2013), o Passivo Circulante também pode ser denominado de Dívida Flutuante e que, para ser reconhecido como Circulante, o Passivo deve ser pago durante o ciclo operacional normal da entidade e/ou no período de até 12 meses subsequentes à data das demonstrações contábeis, sem direito incondicional de diferimento de pagamento em prazo superior a este.

Existem Passivos que não decorrem de obrigações amparadas por títulos de crédito, mas que, embora sua exigibilidade ocorra em prazo superior a 12 meses da data das demonstrações contábeis, pelo princípio da competência, devem ser reconhecidos como Circulante por fazerem parte do Capital Circulante utilizado no ciclo operacional normal da entidade, tais como pagamento de funcionários, transferências governamentais, entre outras despesas operacionais (SLOMSKI, 2013).

Conforme o Manual de Contabilidade Aplicada ao Setor Público - MCASP (BRASIL, 2012), em regra geral, a mensuração da Dívida Flutuante se dá pelo valor original das obrigações, com a conversão à taxa de câmbio vigente na data do Balanço Patrimonial quando se tratar de valores em moeda estrangeira. Em caso de Dívidas Flutuantes decorrentes de obrigações pré-fixadas, a mensuração é efetuada com base em ajustes a valor presente. A Dívida Flutuante decorrente de obrigações pós-fixadas é mensurada com base em ajustes que consideram todos os encargos incorridos até a data do fechamento do Balanço Patrimonial. Frisa-se que as atualizações e os ajustes apurados da Dívida Flutuante são contabilizados em contas redituais.

\subsection{A convergência da Contabilidade Pública do Brasil às Normas Internacionais}


Embora tenha avançado, desde a sanção da Lei Federal n 4.320/1964 até os dias de hoje, com a edição da Lei de Responsabilidade Fiscal, a Contabilidade Pública brasileira ainda vive sob a égide de ordenamentos jurídicos defasados, de caráter extremamente legalista, com necessidade constante de mudanças (SOARES; SCARPIN, 2010). Lima, Santana e Guedes (2009) afirmam que a Lei de Responsabilidade Fiscal e a Lei Federal ${ }^{\circ}$ 4.320/1964, importantes marcos regulatórios da Contabilidade Pública brasileira, não apresentam em sua essência os critérios contábeis fundamentais da Teoria Contábil.

Baseada, fundamentalmente, na Lei Federal n 4.320/1964 e por dar mais atenção aos aspectos legalistas, a Contabilidade Pública deixou o patrimônio, objeto das Ciências Contábeis, em segundo plano e manteve-se centrada no orçamento como cerne dos registros dos fatos ocorridos no setor público. Contudo, com o processo de convergência da Contabilidade Pública às Normas Internacionais, essa situação tende a mudar: o patrimônio passa para primeiro plano como efetivo objeto da Contabilidade Pública (MENESES; PETER, 2012).

Silva (2007) defende a necessidade de que os estudos acerca da Contabilidade Pública progridam em direção à harmonização como medida importante de normatização das regras de registro das transações que movimentam o patrimônio público, possibilitando, de um lado, que os gestores públicos evidenciem de modo claro as ações, projetos e programas, e, de outro, que os administrados realizem julgamentos desses gestores públicos. Entende-se normatização como movimento de uniformidade global e harmonização como processo de comparabilidade global (SILVA, 2007).

No âmbito internacional, o processo de convergência da Contabilidade Pública tem sido conduzido pela International Federation of Accountants - IFAC, entidade internacional que agrega organizações nacionais de profissionais contábeis, responsável pela emissão das Normas Contábeis Internacionais para o Setor Público ou International Public Sector Accounting Standards - IPSAS, em inglês, por meio da International Public Sector Accounting Standards Board - IPASB, com o fito de aumentar a qualidade e a transparência das demonstrações contábeis do setor público (MACEDO et al., 2010; MENESES; PETER, 2012).

No Brasil, o processo de convergência da Contabilidade Pública às Normas Internacionais começou em 2006 quando o Conselho Federal de Contabilidade - CFC criou um grupo de trabalho composto por notáveis contadores da área pública brasileira, denominado Grupo Assessor das Normas de Contabilidade Aplicadas ao Setor Público, com o fim de elaborar e disseminar, entre os profissionais e os diversos usuários, para discussões e debates, propostas das Normas Brasileiras de Contabilidade Aplicadas ao Setor Público NBC TSP conforme as IPSAS da IFAC (BEZERRA FILHO; FEIJÓ, 2012).

Ainda de acordo com Bezerra Filho e Feijó (2012), o primeiro trabalho do Grupo Assessor das Normas de Contabilidade Aplicadas ao Setor Público, no sentido da convergência da Contabilidade Pública brasileira às Normas Internacionais, foi o resgate dos Princípios de Contabilidade para o setor público por meio da Resolução CFC n ${ }^{\circ} 1.111 / 2007$, atualizada pela Resolução CFC $\mathrm{n}^{\circ} 1.282 / 2010$, os quais se tornaram o lastro conceitual na elaboração das dez primeiras Normas Brasileiras de Contabilidade Aplicadas ao Setor Público. Para Macêdo e Klann (2012), a elaboração das dez primeiras Normas Brasileiras de Contabilidade Aplicadas ao Setor Público pelo Grupo Assessor do CFC marcou o início da convergência da Contabilidade Pública, no Brasil, às Normas Internacionais. 
No sentido de apoiar o processo da convergência, o Governo Federal editou duas normas importantes para o setor público: a Portaria do Ministério da Fazenda n ${ }^{\circ} 184$, de 25 de agosto de 2008, e o Decreto Federal $\mathrm{n}^{\circ}$ 6.976, de 7 de outubro de 2009. Em suma, esses instrumentos legais determinam que a Secretaria de Tesouro Nacional - STN deve trabalhar para a promoção da convergência da Contabilidade Pública brasileiras às Normas Internacionais, observando-se os aspectos conceituais e legais vigentes (BRASIL, 2012; BEZERRA FILHO; FEIJÓ, 2012).

Dentre as principais mudanças na Contabilidade Pública brasileira, advindas do processo de convergência às Normas Internacionais, Morais, Vicente e Platt Neto (2012) destacam: a distinção entre orçamento público e Contabilidade Pública; alterações na estrutura das demonstrações contábeis existentes e inclusão de novas demonstrações como a Demonstração do Resultado Econômico (DRE) e Demonstração do Fluxo de Caixa (DFC); a utilização da depreciação no setor público que pode contribuir para a melhoria da accountability governamental; a elaboração do Manual de Contabilidade Aplicada ao Setor Público - MCASP pela Secretaria do Tesouro Nacional - STN, obrigando todos os entes da Federação a se adequarem ao processo de convergência e uniformizando as práticas contábeis públicas por meio do Plano de Contas do Aplicado ao Setor Público - PCASP; a inclusão do Subsistema de Custo na Contabilidade Pública e a aglutinação do Subsistema Financeiro pelo Subsistema Patrimonial e, por fim, a expectativa de melhoria na evidenciação de Ativos e Passivos inclusive os contingentes.

\subsection{A Contabilidade Pública sob o enfoque orçamentário-financeiro versus a Contabilidade Pública sob o enfoque patrimonial}

Segundo Vieira (2010), existem, pelo menos, três visões condicionantes da definição, da forma de cálculo e da caracterização de um Passivo no setor público: a visão orçamentáriofinanceira, na qual os aspectos do orçamento público são preponderantes; a visão estatísticofiscal, pela qual as definições de estatísticas fiscais são utilizadas para fins macroeconômicos; e a visão contábil-patrimonial, na qual os princípios da Contabilidade e as doutrinas contábeis são o cerne. Essas visões têm em comum o fato de estarem fundamentadas em uma base contábil mínima, mas, para que os Passivos sejam devidamente caracterizados, é necessário saber em que instante eles devem ser reconhecidos e é a partir desse ponto que as três visões divergem entre si.

Conforme visto na seção anterior, nos últimos anos, a Contabilidade Pública brasileira adotava a visão orçamentário-financeira no reconhecimento e na evidenciação dos Ativos e Passivos públicos, baseada em um regime contábil conhecido como misto, disposto no art. 35 da Lei Federal $n^{\circ}$ 4.320/1964, em que as receitas eram contabilizadas pelo regime de caixa e as despesas pelo regime de competência, e o orçamento público era o objeto principal da Contabilidade e não o patrimônio público em si. Ocorre que, com a convergência da Contabilidade Pública brasileira às Normas Internacionais, o regime contábil adotado no setor público está mudando para um regime de competência integral, no qual o patrimônio, objeto da Contabilidade, passa a ser o verdadeiro foco do registro contábil público.

O enfoque orçamentário-financeiro da Contabilidade Pública é uma mazela cultural e não propriamente legal tendo em vista que o art. 85 e o art. 89 da Lei Federal no 4.320/1964 já tratavam sobre a contabilização e a evidenciação de todos os elementos patrimoniais, ainda que esses elementos estivessem fora da órbita orçamentário-financeira (VIEIRA, 2010). Para 
Bezerra Filho e Feijó (2012), a visão de que a Contabilidade Pública adota o regime misto como regime contábil é uma interpretação equivocada do art. 35 da Lei Federal no 4.320/1964 que serve somente para registros orçamentários. No âmbito dos registros, do controle e das variações do patrimônio público, o Título IX da Lei Federal $\mathrm{n}^{\circ}$ 4.320/1964, sobre Contabilidade, depreende um cuidado do legislador com os registros contábeis que acudam o enfoque patrimonial (BEZERRA FILHO; FEIJÓ, 2012).

O Quadro 1 sintetiza as principais diferenças entre a Contabilidade Pública sobre o enfoque orçamentário-financeiro e a Contabilidade Pública sobre o enfoque patrimonial.

Quadro 1 - Enfoque orçamentário-financeiro versus enfoque patrimonial

\begin{tabular}{|c|c|c|c|}
\hline ENFOQUE ORÇ & IO-FINANCEIRO & \multicolumn{2}{|c|}{ ENFOQUE PATRIMONIAL } \\
\hline \multicolumn{2}{|c|}{ Forma Legal } & \multicolumn{2}{|c|}{ Essência sobre a Forma } \\
\hline \multicolumn{2}{|c|}{ Regime Contábil: Misto } & \multicolumn{2}{|c|}{ Regime Contábil: Competência } \\
\hline \multicolumn{2}{|c|}{$\begin{array}{c}\text { Objeto: Orçamento Público } \\
\text { (Planejamento e execução a partir do fluxo de caixa) }\end{array}$} & \multicolumn{2}{|c|}{$\begin{array}{c}\text { Objeto: Patrimônio Público } \\
\text { (Recursos à disposição do Estado) }\end{array}$} \\
\hline Ingressos & Gastos & \multirow{2}{*}{ Ativos } & Passivos \\
\hline $\begin{array}{c}\text { Receitas } \\
\text { Orçamentárias }\end{array}$ & $\begin{array}{c}\text { Despesas } \\
\text { Orçamentárias }\end{array}$ & & Patrimônio Líquido \\
\hline \multicolumn{2}{|c|}{ Embasamento: princípios orçamentários } & \multicolumn{2}{|c|}{ Embasamento: princípios contábeis } \\
\hline
\end{tabular}
Fonte: Adaptado de Bezerra Filho e Feijó (2012).

Diversos estudiosos (ANTONY, 1985; AIKEN, 1995; ROBINSON, 2002; TORRES, 2004; CHRISTIAENS, 2004; DUTTA; REICHELSTEIN，2005; RIDDER et al., 2005; PLUMMER et al., 2007; RAMADHAN, 2009 apud MORAIS, VICENTE; PLATT NETO, 2012) apontaram a Contabilidade Pública com enfoque patrimonial e consequente adoção do regime de competência integral como um fator relevante para o melhoramento da evidenciação contábil no setor público. Por conseguinte, Pigatto et al. (2010) concluíram que o uso de regime de caixa ou financeiro, de modo isolado, distorce o valor dos custos operacionais do governo, à medida que os gastos de compromissos legalmente assumidos, mas sem a ocorrência do fato gerador, são apropriados no período indevido.

Reis (2006) afirma que, ainda que haja divergência na legislação, a adoção integral do regime de competência integral só tem a beneficiar a gestão das entidades governamentais com a visualização mais clara da sua situação econômico-financeira e com o controle prévio sobre o seu patrimônio e que o regime de caixa distorce as receitas públicas, por não permitir a visão holística do seu volume no exercício.

Amaral e Lima (2013) concluíram que a nova Contabilidade Pública pode contribuir para dirimir os efeitos dos ciclos políticos no País em função da adoção do enfoque patrimonial e da consequente adoção do regime de competência integral no setor público, no sentido de inibir manipulações de dados contábeis e omissão de informações por razões eleitoreiras.

A não adoção do regime de competência integral, decorrente do enfoque patrimonial, pode resultar em problemas quanto à integridade do balanço, à inferência do desempenho operacional, aos investimentos, às obrigações atuariais, ao endividamento, bem como ao pagamento antecipado de fornecedores (RAMADHAN, 2009). Cruvinel e Lima (2011) apontam como resultado esperado, decorrente da adoção do regime de competência integral pela Contabilidade Pública brasileira, o registro contábil das transações quando da ocorrência 
do fato gerador e não apenas no instante em que houver o desembolso por elas, fazendo com que informações que outrora não compunham as contas do governo passem a ser reconhecidas e evidenciadas no período a que pertencem.

Vasconcelos et al. (2012) apontam que os usuários e preparadores da informação contábil pública acreditam que a mudança do regime misto para o regime de competência integral trará benefícios para a tomada de decisão das entidades governamentais e que essa mudança ocorrerá não somente por exigência e pressão de entidades internacionais, mas também pela crença em benefícios informacionais para a tomada de decisão que essa mudança pode gerar.

Contudo, Chan (2010) alerta que é aconselhável, para países em desenvolvimento como o Brasil, a adoção do regime de competência de forma gradual e progressiva simétrica, conforme Quadro 2, considerando os custos, as necessidades de acúmulo de experiência, o apoio político seguro e a construção de sistemas e desenvolvimento de recursos humanos para tanto.

De imediato, deve haver o reconhecimento e a mensuração correta dos Recursos Financeiros Circulantes e dos Passivos Circulantes. Logo em seguida, os Recursos Financeiros Realizáveis e os Passivos Exigíveis a longo prazo seriam adicionados e, por fim, haveria o reconhecimento e a evidenciação dos Ativos Fixos Operacionais (edifícios públicos e equipamentos, por exemplo).

Quadro 2 - Graus de competência

\begin{tabular}{|c|c|c|}
\hline Grau & Ativos reconhecidos & Passivos reconhecidos \\
\hline Competência fraca & Recursos Financeiros Circulantes & Passivos Circulantes \\
\hline Competência moderada & $\begin{array}{c}\text { Recursos financeiros realizáveis a } \\
\text { longo prazo, além dos Circulantes }\end{array}$ & $\begin{array}{c}\text { Passivos de longo prazo, além dos } \\
\text { Circulantes }\end{array}$ \\
\hline Competência forte & $\begin{array}{c}\text { Recursos de capital, além dos } \\
\text { Circulantes e realizáveis a longo } \\
\text { prazo }\end{array}$ & $\begin{array}{c}\text { Passivos contingentes, além dos } \\
\text { Circulantes e de longo prazo }\end{array}$ \\
\hline
\end{tabular}

Fonte: Adaptado de Chan (2010).

Desse modo, firma-se, até aqui, o entendimento de que o resgate do enfoque patrimonial no registro, no controle, nas evidenciações e nas variações do patrimônio público e a consequente adoção do regime de competência integral reduzirão o efeito dos ciclos políticos na Contabilidade Pública brasileira, a "maquiagem" nas contas do governo e a distorção do valor dos custos operacionais do governo, bem como promoverá um melhoramento na evidenciação da situação econômico-financeira e patrimonial das entidades públicas corroborando melhor tomada de decisão na gestão da res pública.

Todavia, não se pode perder de vista a importância do regime de caixa na Contabilidade Pública para fins estatístico-fiscais exigidos pelo Fundo Monetário Internacional no Government Finance Statistics Manual (GFSM) para reconhecimento de um Passivo (VIEIRA, 2010). Ainda de acordo com Morais, Vicente e Platt Neto (2012), os parlamentares defendem a utilização do regime de caixa sob o argumento de que este oferece mais segurança em termos financeiros ao atenuar os riscos de manipulação dos dados acerca das disponibilidades do governo. 


\subsection{Pesquisas similares acerca dos efeitos da adoção do enfoque patrimonial na Contabilidade Pública}

Severo e Oliveira (2012), ao pesquisarem sobre as principais mudanças previstas para a Contabilidade do setor público no que tange à mensuração e à avaliação do patrimônio, concluíram que a adoção do enfoque patrimonial na Contabilidade Pública brasileira, proveniente do processo de convergência às Normas Internacionais, não invalida o enfoque orçamentário-financeiro previsto na lei e pode representar potencial melhoria em termos de controle e de evidenciação financeira, orçamentária e, principalmente, patrimonial.

Vieira (2010), ao analisar itens das Dívidas Flutuantes constantes dos Balanços Gerais da União (BGU) de 2006 a 2009, verificou casos incontestes de subavaliação de Passivos nos balanços federais analisados e atribuiu a causa dessa subavaliação dos Passivos da União à discrepância existente entre a Contabilidade Pública sob o enfoque orçamentário-financeiro e a Contabilidade Pública sob o enfoque patrimonial, que constitui um dos núcleos de desafio para a convergência da Contabilidade no setor público às Normas Internacionais.

Xavier Júnior, Paulo e Silva (2014), ao analisarem as demonstrações contábeis do ano de 2008, da Prefeitura Municipal de Mossoró, no Rio Grande Norte, concluíram que a convergência da Contabilidade Pública às Normas Internacionais, provocada pela Norma Brasileira de Contabilidade e Técnica (NBC T 16), com a consequente adoção do enfoque patrimonial, aumenta a capacidade informacional contábil no setor público e contribui de forma mais efetiva com a gestão pública.

Segundo Soares e Scarpin (2010), a convergência da Contabilidade Pública às Normas Internacionais, que preconiza a adoção do enfoque patrimonial no registro dos atos e fatos contábeis no setor público, promoverá a melhoria da qualidade e da comparabilidade da informação financeira dos entes públicos, sem prejuízo às suas soberanias, e o atendimento das novas demandas informacionais geradas pela Contabilidade Pública.

Não obstante, Söthe (2009), ao pesquisar acerca dos impactos da mudança do regime misto para o regime de competência integral no reconhecimento e na mensuração do patrimônio público dos governos municipais da microrregião de São Miguel do Oeste, em Santa Catarina, concluiu que essa mudança permite aos usuários da informação contábil pública a correta identificação dos resultados do exercício e do patrimônio dos órgãos públicos no âmbito do enfoque patrimonial.

Noutro giro, Herbest (2010) afirma que alguns estudos empíricos analisados revelaram que as mudanças na Contabilidade Pública, baseadas na adoção de um regime de competência integral, apresentaram pouco ou nenhum sucesso (OUDA, 2005, 2006 e 2007; PARRY, 2005; BLÖNDAL, 2005; BERGMANN, 2006; HUGHES, 2006 e 2007; WYNNE, 2007; OLIORILANTO, 2008; MONSEN, 2008 apud HERBEST, 2010). Atribuiu-se boa parte desse fracasso ao mau ou ao inexistente uso das informações geradas pelo regime de competência integral, bem como à falta de atenção para a implementação das mudanças em detrimento da falta de boa vontade política para tanto.

Desse modo, ressalta-se que o regime de competência integral no setor público, como consequência do enfoque patrimonial na Contabilidade Pública, não possui aceitação unânime. Isso porque, embora haja uma gama de literatura que assevera os benefícios do regime de competência no setor governamental, governos como os da China, do Japão, da Alemanha, da Itália e da Rússia, os quais fazem parte das grandes economias mundiais, não 
adotaram esse enfoque patrimonial decorrente da convergência às Normas Internacionais (WYNNE, 2012 apud ANDRADE; CARVALHO).

\section{Procedimentos Metodológicos}

Este estudo objetiva investigar os efeitos da adoção do enfoque patrimonial sobre a Dívida Pública Flutuante das entidades governamentais, com base na realização de um estudo de caso em uma fundação pública estadual da região Norte do Brasil e do emprego de análise de clusters.

De acordo com a taxionomia proposta por Vergara (2011), a presente pesquisa se caracteriza, quanto a seus fins, como exploratória em virtude de seu caráter de sondagem acerca dos efeitos da adoção do enfoque patrimonial sobre a Dívida Flutuante das entidades públicas, decorrente da convergência da Contabilidade Pública brasileira às Normas Internacionais; e descritiva, em detrimento da exposição dos fenômenos estudados, sem, contudo, explicá-los. Em relação aos seus meios, trata-se de um estudo de caso, em face da circunscrição do trabalho a uma única unidade de análise, examinada detalhadamente; e de pesquisa documental, pois lança mão da legislação contábil do setor público e de documentos conservados no interior de uma fundação pública, disponibilizados em Diário Oficial, em sítios oficiais na Internet e/ou por meio de correspondência eletrônica (e-mail) ou cópias reprográficas cedidas pela unidade de análise como fontes de dados primários.

Escolheu-se como unidade de análise do presente estudo de caso uma fundação pública estadual da região Norte do Brasil por conveniência e pela facilidade de acesso, em profundidade, aos dados da pesquisa. Os principais documentos da unidade de análise que constituíram o conjunto de dados da pesquisa examinados foram o Balanço Patrimonial, o Demonstrativo da Dívida Flutuante, o Demonstrativo de Inscrição de Restos a Pagar, o Balancete Analítico, bem como as Notas de Empenhos (NE) e documentos fiscais pertinentes à Dívida Flutuante da unidade de análise. Todos os dados pertencem ao exercício fiscal de 2012. A escolha do exercício fiscal de 2012, neste estudo, justifica-se pelo fato de ser o exercício financeiro encerrado mais atual da unidade de análise. Omitiu-se a razão social da fundação pública estadual estudada por razões éticas tendo em vista que não se obteve autorização para divulgação da razão social dessa unidade.

O Quadro 3 expressa, de forma sucinta, o volume da Dívida Flutuante da unidade de análise, objeto de estudo desta pesquisa.

Quadro 3 - Volume da Dívida Flutuante da Unidade de Análise

\begin{tabular}{|l|r|}
\hline \multicolumn{1}{|c|}{ Descrição } & \multicolumn{1}{|c|}{ Valor em reais (R\$) } \\
\hline Consignações & $5.359,65$ \\
\hline Depósitos & 0,00 \\
\hline Restos a Pagar Processados de Exercícios Anteriores & 0,00 \\
\hline Restos a Pagar Não Processados de Exercícios Anteriores & 0,00 \\
\hline Restos a Pagar Processados - 2012 & $71.599,91$ \\
\hline Restos a Pagar Não Processados - 2012 & $130.043,08$ \\
\hline \multicolumn{1}{|c|}{ Total da Dívida Flutuante } & $207.002,64$ \\
\hline
\end{tabular}

Fonte: Elaborado pelos autores.

41 ISSN 2175-8069, UFSC, Florianópolis, v. 11, n. 23, p. 31-52, mai./ago. 2014 
O Quadro 4 detalha, por Nota de Empenho (NE) e objeto do gasto, os valores que compõem os Restos a Pagar constantes da Dívida Flutuante da unidade de análise. O valor de $\mathrm{R} \$ 5.359,65$ (cinco mil trezentos e cinquenta e nove reais e sessenta e cinco centavos) se refere a apenas uma consignação de contribuição previdenciária retida (descontada) do empregado assegurado, conforme Nota de Empenho no 365 de 7 de dezembro de 2012.

Quadro 4 - Detalhamento dos Restos a Pagar da Unidade de Análise

\begin{tabular}{|c|c|c|c|c|}
\hline \multicolumn{2}{|c|}{$\begin{array}{c}\text { Nota de } \\
\text { Empenho }\end{array}$} & \multirow{2}{*}{ Objeto do gasto } & \multicolumn{2}{|c|}{ Valor $(\mathrm{R} \$)$} \\
\hline $\mathrm{N}^{\mathrm{o}}$ & Data & & $\begin{array}{c}\text { Não } \\
\text { Processados }\end{array}$ & Processados \\
\hline 037 & $02 / 02 / 2012$ & Fornecimento de tíquete-alimentação & - & $54.877,72$ \\
\hline 038 & $02 / 02 / 2012$ & Serviços de segurança e vigilância & $88.014,78$ & - \\
\hline 039 & $02 / 02 / 2012$ & Serviços de recrutamento de estagiários & $11.970,80$ & - \\
\hline 135 & $16 / 05 / 2012$ & Serviço gráfico de sinalização & - & 117,60 \\
\hline 191 & $25 / 06 / 2012$ & Serviços de telefonia fixa & $3.146,50$ & - \\
\hline 195 & $02 / 07 / 2012$ & Aquisição de cartuchos de tinta/toner para impressoras & $5.901,00$ & - \\
\hline 281 & $11 / 09 / 2012$ & Serviços de manutenção em ar-condicionado & $9.578,00$ & - \\
\hline 300 & $25 / 09 / 2012$ & Aquisição de material permanente esportivo & 570,00 & - \\
\hline 332 & $25 / 10 / 2012$ & Serviços de organização de festas e eventos & $5.500,00$ & - \\
\hline 336 & $14 / 11 / 2012$ & Aquisição de material de copa e cozinha & 462,00 & - \\
\hline 355 & $22 / 11 / 2012$ & Serviço de confecção de banner & 200,00 & - \\
\hline 377 & $07 / 12 / 2012$ & Obrigações patronais & - & $16.604,59$ \\
\hline 382 & $20 / 12 / 2012$ & Aquisição de materiais permanentes de informática & $3.700,00$ & - \\
\hline 384 & $20 / 12 / 2012$ & Aquisição de material de consumo para veículo & $1.000,00$ & - \\
\hline & & Total de Restos a Pagar & $130.043,08$ & $71.559,91$ \\
\hline
\end{tabular}

Fonte: Elaborado pelos autores.

A coleta dos dados ocorreu de 11 a 21 de novembro de 2013. Os dados sobre o volume da Dívida Flutuante da entidade foram extraídos do Balanço Patrimonial, publicado no Diário Oficial do Estado, 25 de março de 2013. Em seguida, foram solicitadas da unidade de análise, por meio de requerimento baseado na Lei de Acesso à Informação (Lei Federal $n^{\circ}$ 12.527, de 18 de novembro de 2011), cópias reprográficas do seu Demonstrativo da Dívida Flutuante, do seu Demonstrativo de Inscrição de Restos a Pagar e do Balancete Analítico de suas contas contábeis, referentes ao ano de 2012. Por fim, para análise qualitativa mais detalhada e aprofundada sobre a ocorrência ou não dos fatos geradores da Dívida Flutuante da fundação pública estadual, examinada no ano de 2012, requereu-se de seu Diretor-Presidente a permissão para passar vista nos autos que instruíram o empenho das despesas constantes dos Quadros 3 e 4.

A eleição da Dívida Flutuante para análise dos efeitos da adoção do enfoque patrimonial pela Contabilidade Pública brasileira decorrente do processo de convergência às Normais Internacionais ocorreu em virtude dos riscos fiscais que pode haver quando o endividamento público não é devidamente registrado, controlado e evidenciado. A análise dos efeitos da adoção do enfoque patrimonial sobre a Dívida Pública Flutuante da entidade governamental examinada se baseou nas Normas Brasileiras de Contabilidade e Técnica NBC T 16.2 e 16.5, no Manual de Contabilidade Aplicada ao Setor Público - MCASP, no Plano de Contas Aplicado ao Setor Público - PCASP e na revisão de literatura.

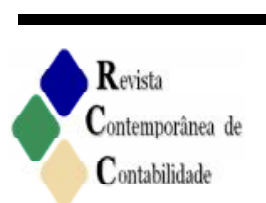


A fragilidade da presente pesquisa reside no fato de que estudos de caso não costumam oferecer muitas bases para generalizações científicas e não possuem condução metodológica bem definida pela literatura como ocorre com as análises estatísticas (YIN, 2010). Todavia, os resultados alcançados e as contribuições esperadas com este estudo não são invalidados por essa fragilidade haja vista suas conclusões poderem servir de parâmetro para pesquisas semelhantes aplicadas em outras entidades públicas. Além do mais, os critérios de análise de resultados adotados, neste estudo, são argumentos válidos, imparciais, replicáveis e sistemáticos.

\section{Resultados e Análises}

Conforme visto anteriormente, com a convergência da Contabilidade Pública às Normas Internacionais, as entidades governamentais deverão apresentar seus Passivos em Circulantes e Não Circulantes, como grupos de contas distintos no Balanço Patrimonial. Dessa forma, a Dívida Pública Flutuante, que antes integrava o Passivo Financeiro das entidades governamentais, passa a ser evidenciada no grupo de contas Passivo Circulante no Balanço Patrimonial.

Logo, a primeira conclusão que se faz a respeito de um dos efeitos da adoção do enfoque patrimonial sobre a Dívida Pública Flutuante é de ordem taxionômica, no que tange ao entendimento e à classificação de Passivos públicos entre Circulante e Não Circulante, bem como estrutural, no que concerne à nova forma de evidenciação da Dívida Pública Flutuante no Balanço Patrimonial que se aproxima ainda mais da forma como os Passivos são evidenciados na iniciativa privada.

Contudo, Vieira (2010) observa que, com a mudança na evidenciação da Dívida Flutuante e da Dívida Fundada ou Consolidada de acordo com o modelo proposto pelas novas Normas de Contabilidade Pública, em que os Passivos serão agrupados em Circulantes e Não Circulantes, parte dos valores da Dívida Fundada estará diluída em grupos de contas diferentes. Para resolver esse problema, será necessário o uso de Notas Explicativas.

Por conseguinte, a NBC T 16.5, que estabeleceu critérios para o registro contábil de atos e fatos que podem afetar o patrimônio público, assevera que o registro dos fenômenos patrimoniais deve ser tempestivo, portanto no momento em que os fenômenos ocorrem, devendo ainda ser divulgados em tempo hábil para os usuários da informação contábil. A norma dispõe também que os registros contábeis, no setor público, devem ser efetuados de modo analítico, evidenciados nas demonstrações contábeis do período a que pertencem, reconhecidos pelos seus fatos geradores de tal maneira que independam da execução orçamentária.

O art. 58 da Lei Federal no 4.320/1964 diz que o empenho da despesa pública é o ato emanado de autoridade competente que gera para o Estado uma obrigação de pagamento pendente ou não de implemento de condição. Sob o enfoque orçamentário-financeiro, essa obrigação é financeira para fins de cálculo de superávit financeiro e trata de comprometimento de disponibilidade financeira da entidade governamental. Logo, essa obrigação não é uma obrigação patrimonial decorrente de um fato gerador ocorrido por uma condição já implementada. Portanto, o simples empenho de uma despesa não afeta o patrimônio público e não gera para o Estado um Passivo em face da não ocorrência do fato gerador (BRASIL, 2012). 
O Manual de Contabilidade Aplicada ao Setor Público - MCASP (BRASIL, 2012) preconiza que, quando o fato gerador ocorrer antes do empenho ou entre a fase de empenho e liquidação da despesa, deve-se registrar o Passivo exigível junto com uma etapa intermediária denominada "em liquidação" para que haja uma diferenciação entre empenhos não liquidados, ao longo ou ao final do exercício financeiro, que geraram ou não obrigação presente. Lembrando que a liquidação da despesa pública, nos termos da Lei Federal n 4.320/1964, é verificação do direito líquido e certo adquirido pelo credor, com base em documentos comprobatórios, tais como notas fiscais e faturas, que sustentam a causa do crédito. Em outras palavras, pode-se dizer que a liquidação da despesa pública é a verificação de um Passivo exigível ocorrido.

Ante o exposto até aqui, para melhor exposição dos dados examinados, agrupa-se a Dívida Flutuante da unidade de análise do presente estudo de caso em três clusters, conforme Quadro 5.

Quadro 5 - Clusters resultante da Dívida Flutuante registrada no Balanço Patrimonial de 2012

\begin{tabular}{|l|l|r|}
\hline \multicolumn{1}{|c|}{ Clusters } & \multicolumn{1}{|c|}{ Descrição } & \multicolumn{1}{c|}{$\begin{array}{c}\text { Volume da Dívida } \\
\text { Flutuante }(\mathrm{R} \$)\end{array}$} \\
\hline Cluster 1 & Despesas empenhadas, cujo fato gerador não ocorreu. & $24.892,70$ \\
\hline Cluster 2 & Despesas empenhadas, cujo fato gerador já tenha ocorrido. & $105.150,38$ \\
\hline Cluster 3 & Despesas empenhadas e liquidadas, cujo fato gerador já tenha ocorrido. & $76.959,56$ \\
\hline & Total & $207.002,64$ \\
\hline
\end{tabular}

Fonte: Elaborado pelos autores.

Em pesquisa mais detalhada de documentos fiscais da unidade de análise, identificouse ainda mais um cluster: Passivos Circulantes, cujos fatos geradores ocorreram no ano de 2012, mas que não foram inscritos como Restos a Pagar, reconhecidos apenas no exercício subsequente, tendo sido empenhados, liquidados e pagos a expensas do orçamento de 2013, conforme Quadro 6.

Quadro 6 - Cluster resultante de Dívidas Flutuantes não registradas no Balanço Patrimonial de 2012

\begin{tabular}{|c|c|c|}
\hline \multicolumn{1}{|c|}{ Cluster } & \multicolumn{1}{|c|}{ Descrição } & $\begin{array}{c}\text { Volume da Dívida } \\
\text { Flutuante }(\mathrm{R} \$)\end{array}$ \\
\hline Cluster 4 & $\begin{array}{l}\text { Passivo com fato gerador ocorrido no exercício anterior, mas } \\
\text { reconhecido somente no exercício posterior. }\end{array}$ & $245.231,09$ \\
\hline
\end{tabular}

Fonte: Elaborado pelos autores.

A Tabela 1 expressa, de forma sintetizada e parcial, centrada apenas na Dívida Flutuante, objeto de estudo desta pesquisa, o Balanço Patrimonial da unidade de análise do presente estudo de caso antes do enfoque patrimonial da nova Contabilidade Pública brasileira.

Tabela 1 - Dívida Flutuante no Balanço Patrimonial da unidade de análise sob o enfoque orçamentário-financeiro

\begin{tabular}{|c|c|c|c|}
\hline \multicolumn{3}{|c|}{ PASSIVO FINANCEIRO } & $207.002,64$ \\
\hline DEPÓSITOS & & $5.359,65$ & - \\
\hline - Consignações & $5.359,65$ & - & - \\
\hline
\end{tabular}

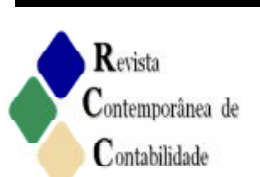


Efeitos do enfoque patrimonial na dívida pública flutuante: ....

\begin{tabular}{|c|c|c|c|}
\hline - Depósitos - Diversas Origens & 0,00 & - & - \\
\hline OBRIGAÇÕES POR EMPENHO & & $201.642,99$ & - \\
\hline - $\quad$ Restos a Pagar - Anos Anteriores & 0,00 & - & - \\
\hline - $\quad$ Restos a Pagar - Processados & $71.599,91$ & - & - \\
\hline - Restos a Pagar - Não Processados & $130.043,08$ & - & - \\
\hline
\end{tabular}

Fonte: Elaborada pelos autores.

Tendo em vista que o enfoque patrimonial leva em consideração o regime contábil de competência integral e reconhece como Passivo da entidade apenas as obrigações cujo fato gerador já tenha ocorrido por uma condição já implementada independentemente da execução orçamentária, as Dívidas Flutuantes, constantes do Cluster 1, no valor total de R $\$ 24.892,70$ (vinte e quatro mil, oitocentos e noventa e dois reais e setenta centavos), não são registradas nem evidenciadas no Balanço Patrimonial, pois seus fatos geradores ainda não ocorreram e/ou não foram reconhecidos, podendo ser evidenciadas como Passivos Contingentes em Notas Explicativas (SLOMSKI, 2013; VIEIRA, 2010). Noutro giro, as Dívidas Flutuantes dos Clusters 2, 3 e 4, sob o enfoque patrimonial, devem ser registradas e evidenciadas no Balanço Patrimonial pela ocorrência e reconhecimento de seus fatos geradores. A Tabela 2 expressa, de forma sintetizada e parcial, centrada apenas na Dívida Flutuante, objeto de estudo desta pesquisa, o Balanço Patrimonial da unidade de análise do presente estudo de caso sob o enfoque patrimonial da nova Contabilidade Pública brasileira.

Tabela 2 - Dívida Flutuante no Balanço Patrimonial da unidade de análise sob o enfoque patrimonial

\begin{tabular}{|c|c|c|c|}
\hline \multicolumn{3}{|l|}{ PASSIVO CIRCULANTE } & \multirow{2}{*}{$\begin{array}{r}427.341,03 \\
-\end{array}$} \\
\hline DEPÓSITOS & & $5.359,65$ & \\
\hline - Consignações & $5.359,65$ & - & - \\
\hline - Depósitos - Diversas Origens & 0,00 & - & - \\
\hline OBRIGAÇÕES EM CIRCULAÇÃC & & $421.981,38$ & - \\
\hline - Obrigações a Pagar & $421.981,38$ & - & - \\
\hline
\end{tabular}

Fonte: Elaborada pelos autores com base no modelo proposto por Slomski (2012).

Observa-se, com a mudança do enfoque orçamentário-financeiro para o enfoque patrimonial decorrente da convergência da Contabilidade Pública às Normas Internacionais, que havia uma subavaliação da Dívida Flutuante da entidade pública tomada como unidade de análise do presente estudo de caso em 51,56\%. Essa subavaliação é perigosa tendo em vista que ela influencia, diretamente, o resultado patrimonial das entidades governamentais, culminando em superávit ou déficit financeiro, dependendo do caso. Portanto, conclui-se, como outro efeito da adoção do enfoque patrimonial na Dívida Flutuante das entidades públicas, melhoria na evidenciação qualitativa e quantitativa do Passivo das entidades governamentais, contribuindo, dessa forma para gestão fiscal transparente e accountability governamental, de acordo com a revisão de literatura.

\section{Conclusões e Recomendações para Futuros Estudos}

Este estudo objetivou investigar os efeitos da adoção do enfoque patrimonial sobre a Dívida Pública Flutuante das entidades governamentais, com base na realização de um estudo 
de caso em uma fundação pública estadual da região Norte do Brasil e do emprego de análise de clusters.

Por meio de pesquisa exploratória, descritiva e documental, com uma abordagem qualitativa, baseada em dados primários, concluiu-se que, com adoção do enfoque patrimonial e consequente regime de competência integral no registro e evidenciação do patrimônio público, decorrente do processo de convergência da Contabilidade Pública brasileira às Normas Internacionais, a Dívida Pública Flutuante, cujos fatos geradores já tenham ocorrido e foram reconhecidos, embora continue sendo evidenciada no Balanço Patrimonial, passa a configurar no grupo de contas do Passivo Circulante, outrora, Passivo Financeiro. Portanto, um dos efeitos é taxionômico, no que tange ao entendimento e classificação de Passivos públicos entre Circulante e Não Circulante, bem como estrutural, no que concerne à nova forma de evidenciação da Dívida Pública Flutuante no Balanço Patrimonial que se aproxima ainda mais da forma como os Passivos são evidenciados na iniciativa privada.

Com a mudança do enfoque orçamentário-financeiro para o enfoque patrimonial decorrente da convergência da Contabilidade Pública às Normas Internacionais, verificou-se uma subavaliação da Dívida Flutuante da entidade pública tomada como unidade de análise do presente estudo de caso em 51,56\%. Essa subavaliação é perigosa tendo em vista que ela influencia, diretamente, o resultado patrimonial das entidades governamentais, culminando em superávit ou déficit financeiro, dependendo do caso. Portanto, conclui-se, como outro efeito da adoção do enfoque patrimonial na Dívida Flutuante das entidades públicas, melhoria nas evidenciações qualitativa e quantitativa do Passivo das entidades governamentais, contribuindo, dessa forma para gestão fiscal transparente e accountability governamental, de acordo com a revisão de literatura.

O resgate do enfoque patrimonial na Contabilidade Pública brasileira pode reduzir o efeito dos ciclos políticos no registro e evidenciação do patrimônio público e a "maquiagem" nas contas do governo embora seja sabido que um regime de competência integral não esteja totalmente imune à famigerada "contabilidade criativa". Cumpre ainda frisar a importância do regime de caixa na Contabilidade Pública para fins estatístico-fiscais exigidos pelo Fundo Monetário Internacional no Government Finance Statistics Manual (GFSM) para reconhecimento de um Passivo, bem como para a mitigação dos riscos de manipulação dos recursos financeiros do governo.

Sabe-se que o regime de competência integral no setor público não possui aceitação unânime, haja vista, conforme visto anteriormente, alguns países partícipes das grandes economias mundiais, como a China, o Japão, a Alemanha, a Itália e a Rússia, não adotarem esse enfoque patrimonial decorrente da convergência às Normas Internacionais, seja por não utilização da informação gerada pela Contabilidade Pública com enfoque patrimonial, seja pela não falta de importância política dada às Normas Internacionais.

Contudo, os resultados da presente pesquisa coadunam com estudos anteriores que defendem que a adoção do enfoque patrimonial pela Contabilidade Pública brasileira, decorrente da convergência desta às Normas Internacionais, não somente melhora a qualidade do registro e da evidenciação do patrimônio público, mas ainda corrobora para atenuar a "maquiagem" das contas públicas, motivadas por fins eleitoreiros, à medida que se identificou uma subavaliação do endividamento da unidade de análise assim como na pesquisa de Vieira (2010) nos Balanços Gerais da União - BGU de 2006 a 2009.

Em se tratando de pesquisas futuras, sugere-se a replicação desta pesquisa em outros grupos de contas patrimoniais, bem como em outras entidades públicas para fins de 
comparação, bem como a transformação deste estudo de caso em um caso para ensino e aprendizagem em Administração e Contabilidade Pública.

\section{Referências}

AMARAL, Guilherme Fernandes; LIMA, Diana Vaz de. A contribuição da nova Contabilidade Pública sobre os efeitos dos ciclos políticos no Brasil. Revista Ambiente Contábil, Natal, n. 2, p. 173-189, jul./dez. 2013. Disponível em:

<http://periodicos.ufrn.br/ambiente/article/view/4156> Acesso em: 11 nov. 2013.

ANDRADE, Maria Elisabeth Moreira Carvalho; CARVALHO, Luiz Nelson Guedes de. Análise da adoção do regime de competência no setor público internacional. Revista FSA, Teresina, n. 1, p. 40-58, jan./mar. 2013. Disponível em:

<http://dx.doi.org/10.12819/2013.10.1.3> Acesso em: 11 nov. 2013.

BALL, Ian. New development: transparency in the public sector. Public Money \& Management, Londres, n. 1, p. 34-40, 2012.

BEZERRA FILHO, João Eudes; FEIJÓ, Paulo Henrique. A nova Contabilidade Aplicada ao Setor Público: o futuro chegou. Revista do TCE-PE, Recife, n. 19, p. 28-61, dez. 2012. Disponível em: <http://periodicos.tce.pe.gov.br/seer/ojs-2.3.6/index.php/Revista_TCEPE/index> Acesso em: 11 nov. 2013.

BEZERRA FILHO, João Eudes. Contabilidade Pública: teoria, técnica de elaboração de balanços e questões. 3. ed. Rio de Janeiro: Elsevier, 2008.

BEM, Augusto Pinho de. As dificuldades de recuperação da Zona do Euro frente às amarras institucionais e a estratégia alemã. Revista Indicadores Econômicos FEE, Porto Alegre, n. 2, p. 95-108, abr./jun. 2013. Disponível em:

<http://revistas.fee.tche.br/index.php/indicadores/article/view/2787/3121 > Acesso em: 11 nov. 2013.

BRASIL. Lei no 4.320, de 17 de março de 1964. Estatui normas gerais de direito financeiro para elaboração e controle dos orçamentos e balanços da União, dos estados, dos municípios e do Distrito Federal. Diário Oficial [da] República Federativa do Brasil, Poder Executivo, Brasília, DF, 23 mar. 1964, Seção 1, p. 2745.

BRASIL. Ministério da Fazenda. Secretaria do Tesouro Nacional (STN). Portaria STN n ${ }^{\circ} 437$ de 12 de julho de 2012. Aprova as Partes II - Procedimentos Contábeis Patrimoniais, III Procedimentos Contábeis Específicos, IV - Plano de Contas Aplicado ao Setor Público, V Demonstrações Contábeis Aplicadas ao Setor Público, VI - Perguntas e Respostas, VII Exercício Prático, da $5^{\text {a }}$ edição do Manual de Contabilidade Aplicada ao Setor Público (MCASP). Diário Oficial [da] República Federativa do Brasil, Poder Executivo, Brasília, DF, 13 jul. 2012, Seção 1, p. 84. 
CHAN, James L.. As NICSPS e a Contabilidade Governamental de Países em Desenvolvimento. Revista de Educação e Pesquisa em Contabilidade, Brasília, n. 1, p. 117, jan./abr. 2010. Disponível em:

<http://www.repec.org.br/index.php/repec/article/view/145> Acesso em: 11 nov. 2013.

COELHO, Mary Cristine; CRUZ, Flávio da; PLATT NETO, Orion Augusto. A informação contábil como ferramenta de auxílio no exercício do controle social. Revista Contabilidade Vista \& Revista, Belo Horizonte, n. 3, p. 163-184, jul./set. 2011. Disponível em: <http://web.face.ufmg.br/face/revista/index.php/contabilidadevistaerevista/article/view/700> Acesso em: 11 nov. 2013.

CONCEIÇÃO, Kelly Bonifácio da. Estudo evolutivo da Contabilidade Pública no Brasil e as ações do Conselho Federal de Contabilidade diante dos novos rumos da Contabilidade Aplicada ao Setor Público. 2012. 111 f. Dissertação (Mestrado em Ciências Contábeis) - Curso de Pós-Graduação em Ciências Contábeis, Faculdade de Administração e Finanças da Universidade do Estado do Rio de Janeiro, Rio de Janeiro, 2012.

CONSELHO FEDERAL DE CONTABILIDADE (CFC). Resolução $n^{\circ} 1.129$, de 21 de novembro de 2008: aprova a NBC T 16.2 - patrimônio e sistemas contábeis. Diário Oficial [da] República Federativa do Brasil, Poder Executivo, Brasília, DF, 25 nov. 2008, Seção 1, p. 81. Disponível:

$<$ http://www.cfc.org.br/sisweb/sre/detalhes_sre.aspx?Codigo=2008/001129 > Acesso em: 11 nov. 2013.

CONSELHO FEDERAL DE CONTABILIDADE (CFC). Resolução $\mathrm{n}^{\circ} 1.132$, de 21 de novembro de 2008: aprova a NBC T 16.5 - registro contábil. Diário Oficial [da] República Federativa do Brasil, Poder Executivo, Brasília, DF, 25 nov. 2008, Seção 1, p. 82. Disponível em: 〈http://www.cfc.org.br/sisweb/sre/detalhes_sre. aspx?Codigo=2008/001132> Acesso em: 11 nov. 2013.

CRUVINEL, Daniel Pereira; LIMA, Diana Vaz de. Adoção do regime de competência no setor público brasileiro sob a perspectiva das normas brasileiras e internacionais de Contabilidade. Revista de Educação e Pesquisa em Contabilidade, Brasília, n. 3, p. 69-85, set./dez. 2011. Disponível em: 〈http://www.repec.org.br/index.php/repec/article/view/185> Acesso em: 11 nov. 2013.

HERBEST, Fabrício Augusto. Regime de competência no setor público: a experiência de implementação de diversos países. In: CONGRESSO ANPCONT, 4., 2010, Natal. Anais eletrônicos... São Paulo: ANPCONT, 2010. Disponível em:

<http://www.fucape.br/_public/producao_cientifica/2/Fabricio\%20Herbest.pdf $>$ Acesso em: 20 jun. 2014.

IUDÍCIBUS, Sérgio de. Teoria da Contabilidade. 10. ed. São Paulo: Atlas, 2010.

JUND, Sérgio. Administração, Orçamento e Contabilidade Pública: teoria e questões. 3. ed. Rio de Janeiro: Elsevier, 2008. 
KOHAMA, Heilio. Contabilidade pública: teoria e prática. 10. ed. São Paulo: Atlas, 2008.

LIMA, Diana Vaz de; SANTANA, Cláudio Moreira; GUEDES, Marianne Antunes. As Normas Brasileiras de Contabilidade Aplicadas ao Setor Público e a legislação contábil pública brasileira: uma análise comparativa à luz da teoria contábil. Contabilidade, Gestão e Governança, Brasília, v. 12, n. 2, p. 15-23, mai./ago. 2009. Disponível em: <http://www.cggamg.unb.br/index.php/contabil/article/view/65> Acesso em: 11 nov. 2013.

MACÊDO, Francisca Francivânia Rodrigues Ribeiro; KLANN, Roberto Carlos. Análise das Normas Brasileiras de Contabilidade Aplicadas ao Setor Público (NBCASP): Um Estudo nas Unidades da Federação do Brasil. In: ENCONTRO DE ADMINISTRAÇÃO PÚBLICA E GOVERNO, 5., 2012, Salvador. Anais eletrônicos... Rio de Janeiro: ANPAD, 2012. Disponível em: <http://www.anpad.org.br/diversos/trabalhos/EnAPG/enapg_2012/2012_EnAPG398.pdf > Acesso em: 11 nov. 2013.

MACEDO, João Marcelo Alves; LOPES, Jorge Expedito de Gusmão; SILVA, Lino Martins da; RIBEIRO FILHO, José Francisco; PEDERNEIRAS, Marcleide Maria Macedo; FEITOSA, Marcos Gilson Gomes. Convergência contábil na área pública: uma análise das percepções dos auditores de TCES, contadores e gestores públicos. Revista de Contabilidade e Organizações, Ribeirão Preto, n. 8, p. 69-91, 2010. Disponível em: <http://www.rco.usp.br/index.php/rco/article/view/143> Acesso em: 11 nov. 2013.

MENESES, Anelise Florêncio de; PETER, Maria da Glória Arrais. Evidenciação das demonstrações contábeis: um estudo sob a óptica do processo de convergência das Normas de Contabilidade Aplicadas ao Setor Público. Revista Gestão Pública: Práticas e Desafios, Recife, n. 5, p. 1-23, out. 2012. Disponível em: <http://www.mpanerevista.kinghost.net/ojs2.2.4/index.php?journal=gppd\&page=article \&op=view\&path[]=96> Acesso em: 11 nov. 2013.

MORAIS, Leandro Morais de; VICENTE, Ernesto Fernando Rodrigues; PLATT NETO, Orion Augusto. A reforma na Contabilidade Pública brasileira e o processo de convergência: implicações e perspectivas. Revista de Informação Contábil, Recife, n. 2, p. 01-20, abr./jun. 2012. Disponível em:

<http://www.revista.ufpe.br/ricontabeis/index.php/contabeis/article/view/411 > Acesso em: 11 nov. 2013.

PIGATTO, José Alexandre M.; HOLANDA, Victor Branco de; MOREIRA, Cristiane R.; CARVALHO, Frederico A.. A importância da contabilidade de competência para a informação de custos governamental. Revista de Administração Pública, Rio de Janeiro, n. 4, p. 821-837, jul./ago. 2010. Disponível em: <http://www.scielo.br/pdf/rap/v44n4/v44n4a04.pdf> Acesso em: 11 nov. 2013.

PIRES, Carlos Eduardo. Dicionário de termos de contabilidade pública. Rio de Janeiro: Ferreira, 2007. 
RAMADHAN, Sayel. Budgetary accounting and reporting practices in Bahraine governmental units: an empirical study. International Business Review, Londres, n. 2, p. 168-183, abr. 2009.

REIS, Heraldo da Costa. Regime de caixa ou de competência: eis a questão. Revista de Administração Municipal - Municípios, Rio de Janeiro, n. 260, p. 37-48, out./dez. 2006. Disponível em: <http://www.oim.tmunicipal.org.br/abre_documento.cfm?arquivo=_repositorio/_oim/_docum entos/4529D07C-0F29-3F8B-9850EEADDC99B4D217122008103654.pdf\&i=268> Acesso em: 11 nov. 2013.

SEVERO, Filipe Ribeiro; OLIVEIRA, Selma Regina Martins. Contabilidade do setor público: um enfoque na mensuração e avaliação do patrimônio. In: SEMINÁRIOS EM

ADMINISTRAÇÃO, 15., 2012, São Paulo. Anais eletrônicos... São Paulo: USP, 2012.

Disponível em:

<http://www.ead.fea.usp.br/semead/15semead/resultado/trabalhospdf/441.pdf $>$ Acesso em: 20 jun. 2014.

SILVA, Lino Martins da. A normatização da Contabilidade Governamental: fatores críticos que impactam as informações dadas aos usuários das informações contábeis. Revista de Educação e Pesquisa e Contabilidade, Brasília, n. 1, p. 25-38, jan./abr. 2007. Disponível em: < http://www.repec.org.br/index.php/repec/article/view/3> Acesso em: 11 nov. 2013.

SLOMSKI, Valmor. Manual de Contabilidade Pública de acordo com as Normas Internacionais de Contabilidade Aplicadas ao Setor Público. 3. ed. São Paulo: Atlas, 2013.

SOARES, Maurélio; SCARPIN, Jorge Eduardo. A convergência da Contabilidade Pública nacional às Normas Internacionais e os impactos na aplicação da DRE na Administração Direta. Revista Catarinense de Ciência Contábil, Florianópolis, n. 27, p. 25-42, ago./nov. 2010. Disponível em: <http://www.atena.org.br/revista/ojs-2.2.3-

06/index.php/CRCSC/article/view/1100> Acesso em: 11 nov. 2013.

SÖTHE, Ari. Diretrizes do IFAC para o regime de competência: impactos nos resultados contábeis dos governos municipais da microrregião de São Miguel do Oeste - SC. 2009. 147 f. Dissertação (Mestrado em Ciências Contábeis) - Programa de Pós-Graduação em Ciências Contábeis da Universidade Regional de Blumenau, Blumenau, 2009.

VASCONCELOS, Adriana Fernandes de; SOUSA, Rossana Guerra de; CANECA, Roberta Lira; NIYAMA, Jorge Katsumi. O regime de competência no setor público brasileiro - uma pesquisa empírica sobre a utilidade da informação contábil. In: CONGRESSO USP DE CONTROLADORIA E CONTABILIDADE, 12., 2012, São Paulo. Anais eletrônicos... São Paulo: USP, 2012. Disponível em: <http://www.congressousp.fipecafi.org/artigos122012/659.pdf $>$ Acesso em: 11 nov. 2013. 
VIEIRA, Laércio Mendes. Nova Contabilidade Governamental brasileira e a evidenciação integral do valor dos passivos no Balanço Patrimonial federal: o caso dos restos a pagar não processados, das despesas de exercícios anteriores e dos passivos reconhecidos por insuficiência de crédito. 2010. 61 f. Monografia (XV Prêmio Tesouro Nacional), Escola de Administração Fazendária, Brasília, 2010. Disponível em:

<http://www3.tesouro.fazenda.gov.br/Premio_TN/XVPremio/financas/2tefpXVPTN/Tema_4 2.pdf> Acesso em: 11 nov. 2013.

VERGARA, Sylvia Constant. Projetos e relatórios de pesquisa em administração. 13. ed. São Paulo: Atlas, 2011.

XAVIER JÚNIOR, Antônio Evirando; PAULO, Edilson; SILVA, José Dionísio Gomes da. Estudo sobre a capacidade informacional das novas estruturas das demonstrações contábeis aplicadas ao setor público. Registro Contábil, Maceió, n. 1, p. 1-19, jan./abr. 2014.

Disponível em: <http://www.seer.ufal.br/index.php/registrocontabil/article/view/1 > Acesso em: 20 jun. 2014.

YIN, Robert K. Estudo de casos: planejamento e métodos. Traduzido por Daniel Grassi. 4. ed. Porto Alegre: Bookman. Tradução de: Case study research: design and methods. 2010. 
